\title{
— L EPISTOLARIO DE JOSÉ GESTOSO (1852-1917) COMO FUENTE PARA EL ESTUDIO DE LA HISTORIOGRAFÍA ARTÍSTICA ESPAÑOLA: ÍNDICE DE AUTORES
}

CARMEN DE TENA RAMÍREZ

Departamento de Historia del Arte. Universidad de Sevilla cdetena@us.es

\begin{abstract}
Resumen: Presentamos el epistolario inédito del erudito sevillano José Gestoso y Pérez (1852-1917), una riquísima fuente de información que contiene la correspondencia recibida por este personaje entre los años 1875 y 1917 . Gestoso consagró su vida al estudio de la historia y del arte sevillano, dedicación que le procuró relaciones amistosas y laborales con destacados personajes del mundo de la cultura europea de finales del siglo XIX y principios del XX, como así lo testimonia su abundante correspondencia. Consideramos que estamos ante una destacada fuente de información epistolar, cuya difusión entre los estudiosos de la historia del arte y la arqueología española puede resultar de gran utilidad.
\end{abstract}

Palabras clave: epistolarios españoles / fuentes para la Historia del Arte / Manuel Gómez-Moreno / Adolfo Fernández Casanova / Vicente Lampérez.

\section{THE EPISTOLARY OF JOSÉ GESTOSO (1852-1917) AS A SOURCE FOR THE STUDY OF THE SPANISH ARTISTIC HISTORIOGRAPHY: AUTHORS INDEX}

Abstract: We want to present the José Gestoso's unpublished epistolary, a rich source of information. It preserves the correspondece received by this person between 1875 and 1917. Gestoso was a researcher of Sevillian Art and History and thanks to his job had relationship with very important people in the XIX century and early XX; this is shown by his correspondence. We considerer this epistolary an important source of information and its diffusion would be useful for the investigations of Art History and Archeology.

Keywords: Spanish epistolaries / sources of Art History / Manuel Gómez-Moreno / Adolfo Fernández Casanova / Vicente Lampérez.

\section{José Gestoso y los estudios histórico- artísticos en España}

El proceso de institucionalización de la Historia del Arte como disciplina universitaria ha recibido durante los últimos años la atención que este campo de estudio merece. Hasta hace poco tiempo, los es- tudios sobre la historia de la historiografía artística española no habían gozado de demasiada popularidad pero afortunadamente, algunos investigadores han querido dedicar su tiempo y su esfuerzo a indagar acerca de los orígenes y la conformación en España de una disciplina joven, como es la Historia del Arte. ${ }^{2}$

\footnotetext{
* Fecha de recepción: 1 de octubre de 2017 / Fecha de aceptación: 10 de febrero de 2017.

1 Este trabajo se ha realizado gracias a un contrato de formación predoctoral (Personal Investigador en Formación P.I.F.) del V Plan Propio de la Universidad de Sevilla. La autora pertenece al Centro de Investigación del Patrimonio Artístico Andaluz (HUM-213) de la Universidad de Sevilla.

2 Al margen de estudios parciales sobre historiografía española, el primer investigador español en reflexionar acerca de los comienzos de la Historia del Arte en España y su desarrollo hasta el presente ha sido el profesor Gonzalo Borrás; de todas sus intervenciones sobre esta cuestión, que son numerosas, destacamos: BORRÁS GUALIS, Gonzalo, 2006, p. 20. Una buena selección bibliográfica sobre los estudios de historiografía artística en España en GONZÁLEZ DE DURANA, Javier, 2008, pp. 87-103. Hace pocos meses finalizó un Proyecto I+D+i dirigido por la profesora Jesusa Vega, centrado en estudiar y analizar los discursos que ha construido la Historia del Arte en España desde su institucionalización en 1904 hasta la actualidad, cuyos resultados han
} 
En este proceso de reconstrucción resulta imprescindible conocer la trayectoria profesional y la producción historiográfica de los estudiosos que contribuyeron a su desarrollo disciplinar. Aunque sus orígenes más remotos se encuentran en el siglo XVI, en la labor llevada a cabo por anticuarios y coleccionistas de arte clásico, los más inmediatos se dieron a finales del siglo XIX entre los miembros del Cuerpo de Archiveros, Bibliotecarios y Anticuarios. Estos fueron los primeros profesionales dedicados a los estudios histórico-artísticos que emplearon un método de trabajo científico en sus investigaciones. ${ }^{3}$ Son en definitiva los precursores de la llamada primera generación de historiadores del arte, de la que fueron figuras destacadas Manuel Gómez-Moreno Martínez y Elías Tormo. ${ }^{4}$

El inicio de la Historia del Arte como disciplina universitaria en España está en el año 1913, con el establecimiento de la cátedra de Historia del Arte de la Facultad de Letras de la Universidad Central. Hasta entonces la Historia de las Bellas Artes, tal y como era conocida esta disciplina, había merecido atención y había sido impartida en otras instituciones educativas, como la Escuela Superior de Diplomática, las Escuelas de Bellas Artes, Ateneos y Sociedades Arqueológicas, Seminarios Diocesanos, etc. En todas ellas se impartía una historia del arte muy vinculada aún a los estudios arqueológicos y viceversa. ${ }^{5}$ De hecho, a finales del siglo XIX no estaba generalizado aún el término "historiador del arte", sino que aquellos que se dedicaban a estos estudios, eran conocidos como arqueólogos. Así se le denominaba a toda persona dedicada al estudio de monumentos antiguos, restos de otras épocas y en fin, todo objeto con cierta antigüedad.

Uno de aquellos "arqueólogos" estudiosos de la historia del arte en España fue José Gestoso ${ }^{6}$ (Sevilla, 1852-1917), profesor por oposición de Teoría e Historia de las Bellas Artes en la Escuela Supe- rior de Industrias y de Bellas Artes de Sevilla. Sin embargo es más conocido por las otras actividades con las que simultaneó esta profesión: ayudante y jefe del Archivo Municipal de Sevilla, ceramista, académico, diseñador, miembro de la Comisión Provincial de Monumentos de Sevilla, coleccionista, literato y bibliófilo. Pero su contribución más importante fue para los estudios de la historia del arte sevillano.?

José Gestoso estuvo muy interesado desde joven en visitar archivos, bibliotecas, mercadillos de antigüedades y colecciones artísticas. Esta afición supo canalizarla a través de los estudios de la Escuela Superior de Diplomática, donde obtuvo el título de Archivero, Bibliotecario y Anticuario. ${ }^{8}$ En 1885 ganó por oposición la cátedra de Teoría e Historia de las Bellas Artes de la entonces Ilamada Escuela de Bellas Artes de Sevilla, circunstancia que le procuró la estabilidad profesional necesaria para poder dedicarse a la investigación de la historia y del arte.

Su método de trabajo está vinculado a la tendencia historiográfica positivista que desde hacía décadas dominaba el panorama científico europeo. Más concretamente, centró su ocupación en la búsqueda de noticias documentales que sirvieran como armazón de una futura historia del arte español, sostenida sobre argumentos fehacientes y fácilmente comprobables, y no sobre hechos quiméricos y fantasiosos, como había sucedido en siglos anteriores. ${ }^{9}$

Pero a la par que ejercía una metódica labor de exhumación de archivos, en busca de las fuentes documentales que proporcionarían el cariz de veracidad a los hechos del pasado, desarrolló una intensa actividad de protección del patrimonio histórico-artístico sevillano. Los monumentos eran, igual que los documentos, testigos de la historia,

visto a la luz en MOLINA, Álvaro (ed.), 2016. También debe atenderse a la labor de recuperación de un personaje fundamental para la conformación de la Historia del Arte como disciplina universitaria en España, D. Elías Tormo; el profesor Luis Arciniega ha trabajado durante los últimos años en ello y fruto de sus esfuerzo se han publicado ARCINIEGA GARCÍA, Luis, 2014 y ARCINIEGA GARCÍA, Luis, 2016.

3 PASAMAR ALZURIA, Gonzalo, 1995, pp. 137-149.

4 BORRÁS GUALÍS, Gonzalo, 2006, p. 20.

${ }^{5}$ Sobre este particular, véase la aportación de MARTíN MARTíNEZ, José, 2016, pp. 69-78.

${ }^{6}$ Sobre la vida de José Gestoso, véase: CASQUETE DE PRADO SAGRERA, Nuria, 2016.

7 Sobre la práctica historiográfica de José Gestoso véase nuestra tesis doctoral "Conocer para conservar; las investigaciones históricas de don José Gestoso y su contribución a la preservación del patrimonio artístico sevillano", defendida en la Universidad de Sevilla en junio de 2018.

${ }^{8}$ A esta titulación hay que sumarle su licenciatura en Derecho Civil y Canónico. Aunque dedicó algunos años a ejercer como jurista, retomó sus aficiones y las convirtió en su medio de vida.

${ }^{9}$ El método historiográfico de José Gestoso está muy vinculado a su formación en la Escuela Superior de Diplomática y a su relación con los ambientes académicos. Como ha quedado demostrado en nuestra tesis doctoral. 
y como tales merecían ser conservados. ${ }^{10}$ Por tanto, los dos pilares sobre los que se asentó su dedicación profesional, al margen de la docencia, son el estudio y la protección del patrimonio histórico-artístico sevillano. Ambas facetas las supo compaginar a la perfección, de forma que no pueden comprenderse la una sin la otra y así lo transmite su epitafio:

GASTÓ SU VIDA EN LA DEFENSA DE LOS INTERESES HISTÓRICOS Y ARTISTICOS DE ESTA CIUDAD; PROCURANDO SOLÍCITO LA CONSERVACION DE SUS TRADICIONES Y MONUMENTOS, CUYA HISTORIA ILUSTRÓ CON SU PLVMA PARA HONRAR A SU PATRIA CUANTO PUDO (...).

Cabe suponer que este afán por la protección monumental hubo de estar fundamentado sobre una serie de valores consustanciales a la formación y al pensamiento de José Gestoso; valores relacionados con las motivaciones que le llevaron al estudio de la historia y el arte de Sevilla. Estos son, en síntesis: el respeto por la historia de Sevilla, en concreto las épocas correspondientes a la Baja Edad Media y al siglo XVl; el aprecio por las tradiciones y su temor a que estas se perdieran; y la reivindicación de la patria y de su pasado imperial. Estos intereses fueron compartidos por los encargados de escribir la historia nacional durante la Restauración: los eruditos profesionales. ${ }^{11}$ Muchos de ellos, sobre todo los miembros del Cuerpo de Archiveros, Bibliotecarios y Anticuarios, pertenecieron al extenso círculo de amistades de José Gestoso. ${ }^{12}$

\section{El epistolario de José Gestoso en la Biblioteca Capitular y Colombina}

Sería faltar a la verdad si dijéramos que nuestro protagonista fue un erudito huraño y misántropo, rodeado de papeles viejos y centrado sólo en sus investigaciones. Nada más lejos de la realidad. A través de sus buenas amistades y también gracias al prestigio forjado entre los estudiosos, supo tejer una amplísima red de contactos con otros estudiosos, historiadores, arqueólogos y otros profesionales de la Historia de diversos lugares de España y del extranjero. De esta circunstancia da buena muestra el epistolario de José Gestoso, una magnífica fuente de información para la investigación histórico-artística.

Por la cláusula séptima de su testamento, Gestoso:

Lega a la Biblioteca Capitular de la Santa Iglesia Catedral de Sevilla, denominada Colombina, los manuscritos de su pluma, sus papeles históricos y literarios $y$, de sus libros, todos los que posea en el momento de su muerte excepto aquellos de que existan ya ejemplares en dicha biblioteca (...). En cuanto a los tomos de Correspondencia particular deseo que asimismo se entreguen a la Colombina, pero encajonados y precintados, con la condición expresa de que no sean abiertos ni puedan ser examinados hasta el año de 1980, a fin de que por lo pronto no tengan los chismosos, aficionados al conocimiento de intimidades personales, motivo de entretenimiento. ${ }^{13}$

Efectivamente, este legado se materializó el 23 de enero de 1918, cuando su viuda María DaguerreDospital, terminó de ordenar y clasificar todos los materiales que lo componían, a saber: "manuscritos de su pluma", "papeles históricos y literarios" y "libros". ${ }^{14}$ Todo ello fue donado a la Biblioteca Capitular y Colombina, establecimiento en el que Gestoso pasó largas jornadas de estudio entre sus libros y documentos. Esta Biblioteca forma parte de la Institución Colombina, perteneciente a la Santa Iglesia Catedral de Sevilla, y allí está debidamente custodiado y conservado este fondo, conocido con el nombre de "Fondo Gestoso" (F.G.).

Este legado no contaba hasta hace poco con instrumentos de descripción a disposición del público que informen acerca de todas sus secciones. Es de tal magnitud este conjunto documental y bibliográfico que los medios humanos no alcanzan a abordarlo en toda su integridad. ${ }^{15}$ Desafortunadamente la cláusula testamentaria tampoco ofrece datos lo suficientemente minuciosos como para permitirnos conocer todas y cada una las secciones que lo conformaban originariamente. Pero la investigación de dicho fondo a los largo de varios años, nos ha permitido conocerlo en profundidad. ${ }^{16}$ En esta ocasión sólo presentamos el epistolario personal de José Gestoso, que por su interés documental, considera-

\footnotetext{
10 Véase RUIZ DE LACANAL RUIZ-MATEOS, María-Dolores, 2013, pp. 59-70.

11 Al respecto véase: PEIRÓ MARTíN, Ignacio, 2006.

12 PASAMAR ALZURIA, Gonzalo; PEIRÓ MARTíN, Ignacio, 1996.

13 Archivo de la Catedral de Sevilla (A.C.S.), Capitular. Secretaría. Correspondencia 11191, s/n.

14 Idem.

15 No obstante, la directora de la Institución Colombina, Nuria Casquete de Prado, está poniendo los medios necesarios para conocer y difundir los contenidos del legado de Gestoso: CASQUETE DE PRADO SAGRERA, Nuria, 2017

16 Esta investigación forma parte de nuestra tesis doctoral ya citada.
} 
mos necesario que sea conocido por los investigadores de la historia, del arte, de la arqueología y en suma del mundo cultural de la España restauracionista.

Cabe destacar que a pesar de haber ingresado el legado en la Biblioteca Capitular y Colombina en 1921, una cláusula del testamento prohibía la consulta de una parte del mismo hasta 1980: la correspondencia y otros manuscritos. En dicho año la edición sevillana del periódico $A B C$ recogió una enigmática noticia, cuyo titular enunciaba: "Fueron abiertas las 'cajas misteriosas' del legado de Gestoso"; ${ }^{17}$ se refería a la puesta a disposición del público del material que permanecía oculto a los lectores. Quizás por aquellos años ochenta poco interesaba husmear entre los papeles viejos de un viejo erudito decimonónico, pero lo cierto es que la apertura de aquellas cajas apenas despertó el interés del panorama académico sevillano. Desafortunadamente y a pesar de su valor, las cartas de Gestoso no han sido consultadas por muchos investigadores.

Sigue $A B C$ informando acerca de la apertura de las misteriosas cajas:

El legado comprende dos cajas grandes (...). Se han hallado en el primer cajón 15 volúmenes numerados del 1 al 15 que contienen 3.924 cartas de fechas comprendidas entre 1875 y 1910 . Hay además con el número 23 otro volumen de 228 cartas y documentos del arquitecto Adolfo Fernández Casanova comprensivos de los años 1882-1915. En el cajón número 2 se encuentran 2.026 cartas coleccionadas en siete volúmenes, numerados del 16 al 22, pertenecientes a los años 1911-1917. ${ }^{18}$

Es decir, se conservan 22 volúmenes de cartas encuadernadas recibidas por José Gestoso: 5.950 cartas de fechas comprendidas entre 1875 y 1917. Además existe un volumen dedicado a recoger íntegramente las 228 cartas recibidas del arquitecto Adolfo Fernández Casanova, de fechas comprendidas entre 1882 y 1915.

A pesar de la falta de instrumentos de descripción del Fondo Gestoso, en el fichero manual de im- presos de la Biblioteca Capitular y Colombina se encuentran las fichas catalográficas que nos informan acerca de esta sección:

-GESTOSO Y PÉREZ, José: Cartas denominadas curiosas por el Sr. Gestoso desde el año 1885 al 1888. 2 volúmenes. Signatura: 114-6bis-5-6.

-GESTOSO Y PÉREZ, José: Cartas dirigidas al Excmo. Sr. D. José Gestoso y Pérez desde el año 1889 al 1917. 19 volúmenes. Signatura: 113-6bis-28-42; 1146bis-1-4.

-GESTOSO Y PÉREZ, José: Cartas dirigidas al Excmo. Sr. Gestoso por D. Adolfo Fernández Casanova desde el año 1882 al 1915. 1 volumen. Signatura: 114-6bis-7.

Es preciso advertir que este epistolario conserva una parte de todas las cartas recibidas por José Gestoso a lo largo de su vida, es decir, habría habido muchas que por contener información comprometida o por otras razones, no habría querido conservar. El gesto de guardar y conservar sus cartas y legarlas a una institución para su consulta por parte de los investigadores, revela la clara intencionalidad y deseo de Gestoso de que la información que estas contenían saliera a la luz. Eso sí, una información seleccionada previamente no sólo por él; también por su mujer, María DaguerreDospital, que fue la encargada de encuadernar y numerar el conjunto epistolar años después de morir su marido. ${ }^{19}$

\section{Los autores de las cartas: amigos y colegas de José Gestoso ${ }^{20}$}

Para ponderar adecuadamente el epistolario de José Gestoso, sólo tenemos que comprobar quiénes fueron sus amigos. Durante toda su juventud llevó una vida social bastante animada, alternando con lo más granado de la sociedad sevillana finisecular. Gracias a los testimonios que conservamos entre sus papeles personales, podemos afirmar que desde muy joven contó con amistades pertenecientes a la élite social y cultural. ${ }^{21}$ Más notable fue el contacto que mantuvo con los artistas sevillanos de la época, como con el escultor Antonio Susillo, a quien asesoró artísticamente ${ }^{22}$ y

\footnotetext{
17 "Fueron abiertas las cajas misteriosas del legado de Gestoso". ABC (Sevilla), 05/11/1980, p. 29.

18 Idem.

19 Todas las cartas están numeradas en tinta roja por ella. También incluyó anotaciones al margen de muchas de ellas, con el objetivo de aclarar su contenido o la filiación de su emisor, de cara a una mejor comprensión de la información contenida por parte del lector.

20 La información referida en este epígrafe ha sido extraída fundamentalmente del estudio y análisis de la correspondencia de José Gestoso, conservada en la Biblioteca Capitular y Colombina. Por otro lado, el círculo de amistades de Gestoso ya ha sido bien estudiado por PLEGUEZUELO HERNÁNDEZ, Alfonso, 1995, pp. IX-XI y CASQUETE DE PRADO SAGRERA, Nuria, 2016, pp. 167-208.

21 Por citar algunos ejemplos, señalaremos las repetidas invitaciones a Gestoso a los bailes de San Telmo organizados por los Montpensier, cf. Invitación a un baile, sin fecha, Biblioteca Capitular y Colombina (B.C.C.), Fondo Gestoso (F.G.), Correspon-
} 
le encargó un busto de Cervantes en barro cocido en el año 1884.23 José García Ramos fue un buen amigo suyo desde joven, ${ }^{24}$ y tuvo un trato cercano a él durante toda su vida. ${ }^{25}$ Otros artistas con los que alternaba llegaban a mostrarle en el taller sus creaciones como es el caso de José Jiménez Aranda, Fernando Tirado, o del escultor Antonio de las Peñas, ${ }^{26}$ aunque también tuvo trato con otros pintores menos conocidos como José Cañaveral y Pérez. ${ }^{27}$ Por todo ello, no nos cabe la menor duda de que hubo de estar interesado por las vanguardias artísticas sevillanas, aunque deberíamos señalar que a lo largo de su vida, se mostró mucho más atraído por lo que antaño se conocía como "arte retrospectivo". Sus contactos con los coleccionistas de antigüedades más destacados de Sevilla así lo confirman, entre ellos, José Domingo Irureta Goyena.

Del mundo artístico provenía la mayor parte de sus amistades más cercanas. El pintor Narciso Sentenach fue uno de sus grandes amigos de juventud, pero la relación se fue enfriando paulatinamente desde la partida de este a Madrid. ${ }^{28}$ Durante su madurez estuvo especialmente relacionado con los hermanos artistas Gonzalo y Joaquín Bilbao, especialmente con el primero, que fue compañero suyo de la Comisión Provincial de Monumentos de SeviIla. ${ }^{29}$ También pertenecía a esta institución otro buen amigo de Gestoso, Virgilio Mattoni. ${ }^{30}$
Desde muy joven y dados sus intereses culturales, entabló amistad con los arqueólogos de la época, entre ellos, Demetrio de los Ríos. A Rodrigo Amador de los Ríos hubo de conocerlo posiblemente gracias a Juan José Bueno, mentor del joven José Gestoso, que era amigo de su padre, José Amador de los Ríos. El hecho de tener una edad similar y de compartir intereses, hubo de ser motivo más que plausible para que desde, al menos, 1882, ${ }^{31}$ compartieran una larga amistad, que, debido a diferencias profesionales, hubo de romperse al cabo de los años. Jorge Bonsor fue otro de los pioneros de la arqueología andaluza. Perteneció al círculo de amistades de Gestoso y contribuyó a ampliarlo al presentarle a personajes de la talla de Pierre Paris, Arthur Engel o Archer Milton Huntington. Otros amigos relacionados con la Arqueología y además pertenecientes al Cuerpo de Archiveros, Bibliotecarios y Anticuarios fueron el célebre arqueólogo José Ramón Mélida, Pelayo Quintero y José Villaamil y Castro; bibliotecario del Palacio Real fue el conde de Las Navas. ${ }^{32}$

José Gestoso tuvo dos grandes amigos arquitectos, que aunque residentes en Madrid, le acompañaron hasta sus últimos días: Vicente Lampérez $z^{33}$ y Adolfo Fernández Casanova, ${ }^{34}$ ambos además de técnicos, fueron estudiosos de la historia de la arquitectura española. De gran importancia para

dencia, 1875-1885, $\mathrm{n}^{\circ}$ 8; invitación a un baile el 28 de noviembre de 1876, idem, $\mathrm{n}^{\circ}$ 9; invitación a una recepción el 8 de diciembre de 1877, idem, $\mathrm{n}^{\circ} 16$; invitación a un baile el 19 de diciembre de 1877, idem, $\mathrm{n}^{\circ} 17$. También es invitado por Maria Letizia de Rute en 1882 a algunas fiestas en su Palacio del Recreo de la Alameda de Hércules, idem, $n^{\circ} 35$ y 36 . El 23 de enero de 1882 asistió a un baile oficial en la Capitanía General, B.C.C., F. G., Apuntes, vol. I, fol. 210r.

22 Susillo dio las gracias a Gestoso por "los apuntes recibido para un proyecto de la figura del Gran Capitán", B.C.C., F.G., Correspondencia, 1875-1885, $n^{\circ}$ 96; otras cartas en el mismo volumen: $n^{\text {os } 102,106,129 .}$

${ }^{23} \mathrm{Idem}, \mathrm{n}^{\circ} 96$.

24 B.C.C., F.G., Correspondencia, 1875-1885, nº 7.

25 Véase B.C.C., F.G., Correspondencia, varios años. También retrató a Gestoso en una ilustración para el relato "Manolillo el Ciego".

${ }^{26}$ Gestoso recoge esas visitas: B.C.C., F.G., Apuntes, vol. I., fol. 195v.

27 Intercambiaron correspondencia de carácter amistoso entre 1875 y 1884, residiendo el pintor fuera de Sevilla. B.C.C., F.G., Correspondencia, 1875-1885, nos 5, 6, 107.

${ }^{28}$ En Madrid, Sentenach se encargó de gestionar varios asuntos pendientes de Gestoso, especialmente aquellos relacionados con la edición de sus libros, véase especialmente B.C.C., F.G., Correspondencia, 1895-1898.

29 De esta amistad de hace eco: LÓPEZ-VALDEMORO, Juan Gualberto, 1918.

30 Para Bilbao y Mattoni, consúltese: B.C.C., F.G., Correspondencia, varios años y números.

31 Primera carta recibida: B.C.C., F.G., Correspondencia, 1875-1885, nº 44, carta de Rodrigo Amador de los Ríos a José Gestoso, fechada el 25/05/1882.

32 Juan Gualberto López-Valdemoro, conde de Las Navas, fue uno de los mejores amigos de Gestoso. Estuvo encargado de escribir su necrológica a petición de las Academias Sevillanas de Buenas Letras y Bellas Artes, y en ella se mostró el cariño que tuvo por Gestoso, cf. LÓPEZ-VALDEMORO, Juan Gualberto, 1918. También ha resaltado la importancia de esta relación: CASQUETE DE PRADO SAGRERA, Nuria, 2016, pp. 190-197.

33 Sobre la importancia de esta figura para la historiografía artística, véase: RIVERA BLANCO, Javier, 2011, pp. 59-90.

${ }^{34}$ La correspondencia mantenida con ambos es muy numerosa, pero es especialmente destacada la que tuvo con Fernández Casanova, de la que se conserva un volumen entero sólo de cartas entre ambas, B.C.C., F.G., Correspondencia, Cartas dirigidas al Excmo. Sr. Gestoso por D. Adolfo Fernández Casanova desde el año 1882 al 1915, 1 vol., sign. 114-6bis-7. 
comprender el desarrollo e institucionalización de la Historia del Arte en España son las cartas de Manuel Gómez-Moreno Martínez, ${ }^{35}$ Elías Tormo ${ }^{36}$ y de otros investigadores extranjeros que trabajaron en nuestro país, como Carl Justi y August Mayer. ${ }^{37}$ La correspondencia mantenida con estas grandes figuras de la Historia del Arte es numerosa, e indicativa del conocimiento de Gestoso acerca de las tendencias historiográficas de su época.

La certeza de que José Gestoso estaba vinculado social y laboralmente con la élite cultural española, se corrobora atendiendo a su amistad con Blanca de los Ríos y la duquesa viuda de Alba, las mujeres más importantes en el panorama cultural de la España de finales del XIX y principios del $X X{ }^{38}$ Blanca de los Ríos fue una escritora de éxito y gran cultura; estaba casada con su también amigo Vicente Lampérez y muy unida a María Daguerre, la esposa de Gestoso. ${ }^{39}$ Por otro lado, María del Rosario Falcó, duquesa viuda de Alba, debió conocerlo en los círculos culturales madrileños, donde les unió la afición por los archivos y bibliotecas.

Y sin alejarnos de la élite social española de la época, destacamos las relaciones de Gestoso con numerosos políticos españoles, muchos de ellos con altos cargos en ministerios o bien, senadores y diputados. El ejemplo más ilustrativo es el de Guillermo J. de Osma. ${ }^{40}$ Como ha señalado Ignacio Peiró, el interés por las antigüedades y por la erudición fue un elemento de prestigio durante esta época de la primera etapa de la Restauración, llegando incluso a ayudar a la promoción de la carrera política. Por tanto, no deben extrañarnos las incursiones historiográficas de figuras señaladas de la aristocracia y de la política española de la Restauración. ${ }^{41}$ Otros personajes de este mismo ambiente que aparecen con frecuencia entre las cartas y papeles de Gestoso son el conde de La Viñaza, José Enrique Serrano Morales, Luis Palomo o Carlos Cañal. ${ }^{42}$

Otro aspecto destacado es la relación de Gestoso con la realeza española. La fama de conservador y monárquico que le precede no es en ningún caso equívoca. Tal y como ha sido investigado por el profesor Álvaro Recio, Gestoso mantuvo contactos muy estrechos con la Casa Real, especialmente con el marqués de Irún durante sus trabajos de restauración en el Alcázar de Sevilla. ${ }^{43}$ Años después, su principal interlocutor fue Emilio $M^{a}$ de Torres, secretario particular del rey Alfonso XIII, con el que mantuvo una larga relación epistolar.

También tuvo amigos sacerdotes y religiosos: el jesuita Juan Bautista Moga, el agustino Diodoro Vaca González, o el franciscano capuchino Fr. Diego de Valencia, con quienes compartía el interés por el arte y la historia.

Falta por mencionar a los amigos sevillanos de Gestoso: abogados, literatos, eruditos y aristócratas; pertenecientes todos ellos a la élite cultural de la Sevilla restauracionista. De ellos conocemos menos detalles, ya que por circunstancias evidentes, apenas se conservan cartas en la correspondencia de Gestoso. Pero teniendo en cuenta los datos de los cuales disponemos, podemos asegurar que entre sus mejores amigos estarían Luis Montoto, Adolfo Rodríguez Jurado, Manuel Gómez Imaz, Francisco Rodríguez Marín, Andrés Parladé y José María Valdenebro, importantes literatos de la época muchos de ellos.

Al margen de esta breve introducción sobre la figura de José Gestoso, su papel como precursor de los estudios de historia del arte en España, y sus célebres amistades, queremos ofrecer a los investigado-

\footnotetext{
35 Además de los numerosos homenajes y semblanzas dedicados a Manuel Gómez-Moreno Martínez, durante los últimos años se han publicado algunos trabajos dedicados al estudio de su labor historiográfica: GARCÍA CUETOS, Ma Pilar, 2008, pp. 8-25; GARCÍA CUETOS, Ma Pilar, 2011, pp. 125-158; GÓMEZ-MORENO CALERA, José Manuel, 2016.

36 ARCINIEGA, Luis (coord.), 2016.

37 BONET CORREA, Antonio, et al. (coord.), 2015; POSADA KUBISSA, Teresa, 1995, pp. 375-380.

${ }_{38}$ La mujer estaba en esta época relegada a un papel muy secundario; aquellas con nombre propio, como las citadas, fueron excepcionales, cf. PEIRÓ MARTíN, Ignacio, 2006, p. 186-187.

39 Indicó María Daguerre: «Fueron estrechísimos siempre los lazos de nuestra fraterna amistad, desde la más tierna infancia; su madre prima de la mía me amamantó durante varias semanas hasta que llegó mi nodriza», cf. B.C.C., F.G., Correspondencia, 1909, n 32 .

40 Sobre la relación entre Osma y Gestoso, véase PLEGUEZUELO HERNÁNDEZ, Alfonso, 1995, pp. X-XI.

${ }^{41}$ PEIRÓ MARTín, Ignacio, 2006, p. 40. El mismo presidente Antonio Cánovas del Castillo fue muy aficionado al estudio de la historia de España.

42 Al respecto, conviene subrayar la importancia en la época restauracionista de las redes de amistades establecidas entre políticos, eruditos, historiadores y académicos, cf. PEIRÓ MARTíN, Ignacio, 2006, p. 283.

43 RECIO MIR, Álvaro, 2009, p. 119-133.
} 
res un índice (Anexo documental) que recoge una mínima parte del epistolario de José Gestoso custodiado en la Institución Colombina de Sevilla. En él presentamos una selección de los interlocutores de José Gestoso, todos ellos relacionados con el estudio de la historiografía artística española: eruditos, artistas, arqueólogos, estudiosos de la historia del arte, arquitectos, coleccionistas..., y las cartas que estos le dirigieron y que se han conservado.

El índice que hemos elaborado recoge el nombre del autor de la correspondencia, los años en los que se encuentran cartas suyas y su numeración. De esta forma, el investigador podrá tener a su alcance un instrumento de descripción sobre el Fondo Gestoso, que aunque parcial, puede facilitar la labor investigadora. Esperamos que con esta contribución ayudemos a difundir los estudios sobre historiografía artística española, la figura de José Gestoso, y la vida y obra de los personajes que formaron parte de su vida.

\section{Bibliografía}

ARCINIEGA GARCÍA, Luis. Elías Tormo (1869-1957) y los inicios de la Historia del Arte en España. Granada. Atrio, 2014.

ARCINIEGA GARCÍA, Luis. Elías Tormo, Apóstol de la Historia del Arte en España. Valencia: Institució Alfons el Magnànim, 2016.

BONET CORREA, Antonio, et al. (coord.). Carl Justi y el Arte Español. Madrid: Centro de Estudios Europa Hispánica, 2015.

BORRÁS GUALÍS, Gonzalo. "A modo de introducción: Cien años de Historia del Arte en España". En: BORRÁS GUALÍS, G.; REYES PALACIOS, A. Diccionario de historiadores españoles del arte. Madrid: Cátedra, 2006.

CASQUETE DE PRADO SAGRERA, Nuria. José Gestoso y Sevilla. Biografía de una pasión. Sevilla: Ayuntamiento, ICAS, 2016.

CASQUETE DE PRADO SAGRERA, Nuria. "El Fondo Gestoso de la Biblioteca Capitular y Colombina: historia y descripción", Isidorianum, 2017, 26, pp. 51-52.

GARCÍA CUETOS, Ma Pilar. "Alejandro Ferrant y Manuel Gómez-Moreno: aplicación del método científico del CEH a la restauración monumental", Loggia. Arquitectura y Restauración, 2008, 21, pp. 8-25.

GARCÍA CUETOS, Ma Pilar. "La renovación de la Historia de la Arquitectura y del Arte en las primeras décadas del siglo XX: Manuel Gómez-Moreno". En: BIEL IBÁÑEZ, M.P.; HERNÁNDEZ MARTÍN, A. (coord.). Lecciones de los maestros. Aproximación histórico-crítica a los grandes historiadores de la arquitectura española. Zaragoza, 2011, pp. 125-158.

GÓMEZ-MORENO CALERA, José Manuel: Manuel Gómez-Moreno Martínez (1870-1970). Granada: Comité Español de Historia del Arte, Atrio, 2016.

GONZÁLEZ DE DURANA, Javier. "Historia del Arte en la España reciente. Métodos, temas y tendencias en los últimos años". En: PELLISTRANDI, B.; SIRINELLI, J.-F. (ed.). L' histoire culturelle en France et en Espagne. Casa de Velázquez: Madrid, 2008.

LÓPEZ-VALDEMORO, Juan Gualberto: "El Licenciado Gestoso", Coleccionismo. Revista mensual de los coleccionistas y curiosos, 1918, X, pp. III-VIII.
MARTÍN MARTíNEZ, José. "Genealogía de la Historia del arte en tiempos de Elías Tormo", en ARCINIEGA GARCÍA, L. (coord.). Elías Tormo, Apóstol de la Historia del Arte en España. Valencia: Institució Alfons el Magnànim, 2016.

MOLINA, Álvaro (ed.). La Historia del Arte en España. Devenir, discursos y propuestas. Madrid: Polifemo, 2016.

PASAMAR ALZURIA, Gonzalo: "De la Historia de las Bellas Artes a la Historia del Arte (La profesionalización de la historiografía artística española). En: GÁLLEGO, J. et al. Historiografía del arte español en los siglos XIX y XX. (Celebrado en Madrid del 22 al 25 de noviembre de 1994). Madrid: Centro de Estudios históricos. Departamento de Arte Diego Velázquez, 1995, pp. 137-149.

PASAMAR ALZURIA, Gonzalo; PEIRÓ MARTíN, Ignacio. La Escuela Superior de Diplomática. Los archiveros en la historiografía española contemporánea. Madrid: ANABAD, 1996.

PEIRÓ MARTíN, Ignacio. Los guardianes de la historia: la historiografía académica de la Restauración. Zaragoza: Institución Fernando el Católico, 2006.

PLEGUEZUELO HERNÁNDEZ, Alfonso. "Presentación". En GESTOSO Y PÉREZ, J. Historia de los barros vidriados. Sevilla: Ayuntamiento, 1995, pp. VII-XXIII.

POSADA KUBISSA, Teresa: "August L. Mayer". En: GÁLLEGO, J. et al. Historiografía del arte español en los siglos XIX y XX. (Celebrado en Madrid del 22 al 25 de noviembre de 1994). Madrid: Centro de Estudios históricos. Departamento de Arte Diego Velázquez, 1995, pp. 375-380.

RECIO MIR, Álvaro. "Alfonso XIII, José Gestoso y el Alcázar de Sevilla". En GONZÁLEZ GÓMEZ, J.M.; MEJÍAS ÁLVAREZ, M.J. Estudios de Historia del Arte. Sevilla: Secretariado de Publicaciones de la Universidad de Sevilla, 2009, vol. I, p. 119-133.

RIVERA BLANCO, Javier: "El comienzo de la historia de la arquitectura en España, Vicente Lampérez y Romea". En BIEL IBÁÑNEZ, M.P.; HERNÁNDEZ MARTÍN, A. (coord.). Lecciones de los maestros. Aproximación Histórico-crítica a los grandes historiadores de la arquitectura española. Zaragoza: Institución Fernando el Católico, 2011, pp. 59-90.

RUIZ DE LACANAL RUIZ-MATEOS, María-Dolores. "José Gestoso y Pérez: teoría y praxis de la conservación". Ge-Conservación, 2013, 4, pp. 59-70.

\section{Anexo documental}

Correspondencia de José Gestoso con arquitectos, arqueólogos, artistas, coleccionistas, eruditos, historiadores del arte y miembros del Cuerpo de Archiveros, Bibliotecarios y Anticuarios (1875-1917).

AGUILERA GAMBOA, Enrique de (marqués de Cerralbo) 1909 vol. 1:128; 1911: 160; 1913: 31, 50; 1914: 307, 319; 1915: 51, 52, 76, 119, 121, 124, 141, 153; 1916 53, 88, 113, 174, 176, 205; 1917: 35.

BALLARDINI, Gaetano

1910 vol.1: 22, 27, 128; 1913: 30, 72, 88, 147.

BARBER, Edwin A.

1915: 191, 275; 1916: 83.

BELMONTE Y CLEMENTE, Fernando

1875-1885: 63; 1885-1888: 110; 1889-1890: 256.

BERMÚDEZ PLATA, Cristóbal

1911: 70; 1913: 35, 53. 
BILBAO, Gonzalo

1893-1894:139; 1899-1900: 57, 75, 105; 1901-1902: 237, 280; 1903-1904: 83, 84; 1905-1906: 56, 158, 167; 1907-1908: 11, 16, 39, 246, 319; 1909: 12, 104; 1911: 48, 111, 124, 133; 1912: 126, 157, 159, 214; 1914: 31, 174; 1915: 229, 271, 284; 1916: 55, 73, 110.

BILBAO, Joaquín

1899-1900: 229; 1903-1904: 219, 222; 1905-1906: 233; 1909: 8, 15, 30; 1910 vol. 1: 117; 1910 vol. 2: 25; 1911: 26: 1914: 244; 1915: 139, 164

BONSOR, Jorge

1885-1888: 91, 121; 1889-1890: 44, 49, 68; 1891-1892 17, 246, 257, 262; 1893-1894: 23, 56; 1895-1898: 30, 47, 188; 1901-1902: 23, 36, 44, 85, 97, 105, 176, 286 , 294; 1903-1904: 7, 96, 103, 108, 211, 216, 276, 301; 1905-1906: 11, 15, 21, 254; 1907-1908: 28, 109, 124, 197, 211, 241, 242, 275, 304; 1909: 23, 105; 1910 vol. 1: 125; 1910 vol. $2: 40,82,110,141$; 1911: 249, 293, 311, 334; 1912: 230, 308, 314; 1913: 93, 188, 199, 235; 1914: 27, 82, 117, 151, 201, 293, 295; 1915: 41, 54, 68, $69,80,87,100,101,102,160,163,172,235,268,272$ 294, 297; 1916: 39, 48, 76, 95, 96, 219, 243, 245, 262, 269, 271, 272; 1917: 10, 12, 13, 27.

CANTAGALLI, Figli di G.

1911: 292, 314, 315, 331; 1912: 2, 4, 32, 155, 194, 227 $253,255,277,325$; 1913: 27, 43, 56, 138, 145, 154, 240, 262; 1917: 47.

CROOKE Y NAVARROT, Juan Bautista (conde de Valencia de Don Juan)

1893-1894: 8, 11, 18, 39, 178; 1895-1898: 138, 222, 375; 1899-1900: 54, 70, 73, 122; 1901-1902: 5, 82, 168 182; 1903-1904: 49, 65, 80

DE LOS RÍOS, Rodrigo Amador

1875-1885: 44, 45, 50, 55, 57, 65, 79, 81, 86, 88, 94, 95 $101,120,134,139,144,153,166,170 ; 1885-1888: 17$, 27, 43, 88, 96, 195, 246; 1889-1890: 14, 138, 145, 150, $157,187,228,232,233,251$; 1891-1892: 10, 14, 19, 21, $25,26,64,71,87,106,109,122,151,171,180,182$, $186,195,198 ; 1893-1894: 6,16,34,46,52,83,84,123$, 169, 207; 1895-1898: 7, 26, 37, 123, 242, 328, 336; 1899-1900: 61, 131, 179; 1901-1902: 47, 81, 134, 170, 180, 193, 198; 1903-1904: 263; 1905-1906: 8, 12, 31, $36,43,73,84,103,113,116,123,207,209,217,222$, 242, 256, 257, 267, 274; 1907-1908: 17, 23, 85, 113, 251, 295, 310; 1909 vol. 1: 69, 73, 83, 129, 154, 158 164, 170; 1909 vol. 2: 9, 42, 54, 113; 1910 vol. 1: 2, 32 $37,74,136 ; 1910$ vol. $2: 8,26,37,88,92,115,131$; 1911: 12, 22, 24, 29, 34, 41, 57, 61, 84, 168, 189, 237; 1912: 19, 37, 268, 275, 288, 292, 296; 1913: 78; 1914: $94,100,106,126,129,132,137,193,198,214,221$, 277, 304, 308, 313, 324; 1915: 4, 23, 58, 63.

ENGEL, Arthur

1889-1890: 119, 122, 155; 1895-98: 273, 305, 306, 334, 364; 1899-1900: 15, 16, 134, 146, 166, 199; 1901-1902: $35,58,60,64,129,281 ; 1903-1904: 39,56,60,89,91$. 1905-1906: 168; 1907-1908: 53, 114, 315; 1909 vol. 1: 39; 1909 vol. 2: 191; 1911: 81, 83; 1913: 136, 148; 1915: 15, 304; 1916: 284.

FERNÁNDEZ CASANOVA, Adolfo

Cartas dirigidas al Excmo. Sr. Gestoso por D. Adolfo Fernández Casanova desde el año 1882 al 1915. 1 volumen. Signatura: 114-6bis-7.

1875-1885: 171, 178, 188, 189; 1885-1888: 8, 40, 48, $77,89,122,126,136,150,157,158,166,169,170$, $176,191,199,200,210,215,216,217,218,224,227$, 229, 236, 242, 248; 1889-1890: 41, 63, 67, 69, 75, 76, $77,79,84,85,89,97,109,117,120,130,140 ; 1895-$ 1898: 377 .
FERNÁNDEZ LÓPEZ, Juan

1891-1892: 1, 18, 46, 48, 51, 53, 62, 63, 83, 89, 137, $140,143,248,253,260,267 ;$; 1895-1898: 79, 89, 193, $313,313,367,368,374 ; 1899-1900: 3,28,31,47,224$, 225; 1901-1902: 50, 59, 63, 77, 162, 163, 169, 178, 216; 1903-1904: 229, 252; 1905-1906: 88, 109, 147, 183, $184,192,203,210,220$; 1910 vol. $2: 86,89,102,109$, 117, 120, 153, 160; 1911: 205, 268; 1912: 350.

FERNÁNDEZ LÓPEZ, Manuel 1893-1894: 100; 1899-1900: 85-170, 1903-1904: 117 , 135, 227, 228, 273, 287; 1905-1906: 18, 25.

GÓMEZ-MORENO GONZÁLEZ, Manuel 1903-1904: 131; 1905-1906: 250.

GÓMEZ-MORENO MARTÍNEZ, Manuel

1895-1898: 117, 134, 172, 210, 248, 274, 337; 18991900: $26,101,125,144,224,231 ; 1901-1902: 46,103$, $152,181,200,273$; 1903-1904: 4, 23, 53, 76, 294, 303, 304; 1905-1906: 80, 100, 115, 122, 154, 230, 232; 1907-1908: 18, 24, 25, 81, 87, 87b, 185, 200, 231, 287; 1909 vol. 1: 92; 1909 vol. 2: 17, 109, 114, 153; 1910 vol. 1: 107; 1911: 159, 167; 1916: 25, 43, 44, 52, 91, 138, 145, 184, 197, 208.

GÓMEZ MILLÁN, Antonio

1914: 133, 138, 173, 196, 199, 206, 213, 227, 256, 269. 1915: 151; 1916: 35, 58, 153, 241, 255, 279, 285.

GÓMEZ MILLÁN, José

1909 vol. 2: 28, 40, 155; 1910 vol. 1: 18, 85, 92, 94; 1910 vol. 2: 106; 1911: 72; 1913: 63; 1914: 140, 170.

HUNTINGTON, Archer Milton

1901-1902: 242; 1903-1904: 10, 11, 37, 41, 42, 63, 66, $97,101,112,115,132,188,191,232,260,272,277$, 286, 302; 1907-1908: 62, 236, 297, 305; 1909 vol. 1: 51 102, 149, 157; 1909 vol.2: 1, 108; 1910 vol. 1: 5, 83; 1911: 42, 107, 223, 227, 332, 344; 1912: 16, 114, 141, 219, 228, 303, 326; 1913: 37; 1914: 280; 1915: 169, 252; 1916: 119 .

IRURETA GOYENA, José

1875-1885: 85,87, 91, 93, 108, 154, 168; 1885-1888: 7 37, 151, 220, 221; 1889-1890: 11, 23, 114; 1891-1892: 58, 110, 258, 264; 1895-1898: 319; 1907-1908: 254; 1909 vol. 2: 50; 1912: 369; 1914:152; 1915: 296, 308; 1916: 34, 56

JUSTI, Carl

1899-1890: 229, 238; 1891-1892: 34，45，136；18931894: 70

LAMPÉREZ Y ROMEA, Vicente

1901-1902: 114, 149, 233; 1903-1904: 141; 1905-1906: 78, 89, 102; 1907-1908: 84, 308, 312; 1909 vol. 1: 62; 1910: 96; 1912: 21, 46, 99, 108, 133, 153, 154, 290, 307, 364; 1913: 83, 92, 113, 120, 126, 162, 191; 1914: 64, 77, 257, 271; 1915: 10, 285, 287; 1916: 2, 268, 282, 287; 1917: 19, 23, 31, 51.

LÓPEZ MARTÍNEZ, Celestino

1907-1908: 126; 1909 vol. 1: 17, 79; 1913: 14; 1915: 269; 1917: 6

MADRAZO Y KUNTZ, Pedro de 1875-1885: 84, 115, 116, 143, 164, 187; 1885-1888: 230, 232; 1889-1890: 104

MARTÍNEZ CUBELLS, Salvador

1875-1885: 152; 1895-1898: 200, 217, 238; 1899-1900: 62, 142; 1901-1902: 34; 1909 vol. 1: 52

MAYER, August

1907-1908: 216; 1909 vol.1: 44; 1909 vol.2: 65, 140, 141, 181; 1910 vol. $1: 72,111 ; 1910$ vol. $2: 6,77 ; 1911$ : 35, 56, 219; 1912: 236, 302, 355, 370; 1913: 63bis, 68, 95; 1914: 131, 169, 179; 1915: 17, 116, 157, 197, 311. 


\section{MÉLIDA ALINARI, Arturo}

1875-1885: 105; 1899-1900: 4, 7, 8, 13, 14, 20, 29, 39, $44,48,51,156,213 ; 1901-1902: 1,3,13,20,22,26,27$, $31,33,40,56,68,83,94$.

MÉLIDA ALINARI, José Ramón

1875-1885: 113, 176, 181; 1885-1888: 36, 46, 206, 222 , 406; 1889-1890: 2, 4, 35, 111, 244, 255; 1891-1892: 11, $102,124,157,197 ;$ 1893-1894: 37, 210, 236; 18951898: 122, 211, 218, 223, 253, 323, 379; 1899-1900: 1, $21,143,163,177,182,189,228 ; 1901-1902: 89,98$, 174, 279; 1903-1904: 9, 116, 120, 137, 154, 162, 166, $170,175,178,185,187$; 1905-1906: 83, 134, 190, 199, 273; 1907-1908: 4, 22, 34, 42, 118, 165, 195; 1909 vol.2: 163, 167; 1910 vol. 1: 80; 1911: 6, 37, 63, 102, $114,122,178,186,190,210,337 ; 1912: 199,244,262$, 265, 281, 299; 1913: 73, 75, 192; 1914: 89, 128, 148, 312, 323; 1915: 1, 170, 312; 1916: 94, 135; 1917: 32.

MESNIL, Jacques 1907-1908: 147, 269; 1909 vol. 1: 7; 1916: 81, 117, 157, $177,194,200$.

MORENO CARBONERO, José 1903-1904: 254; 1909 vol. 1: 56; 1911: 265; 1912: 12 , 165, 171; 1913: 94; 1916: 85; 1917: 42.

MUÑOZ Y MANZANO, Cipriano (conde de la Viñaza) 1885-1888: 29, 39, 45, 71, 114, 142, 156, 190, 205, 240; 1889-1890: 40, 56, 127, 173, 180, 190, 263; 1891-1892: 60; 1893-1894: 43, 53, 157, 165, 230, 257; 1895-1898: 21; 1901-1902: 100.

OSMA, Guillermo J. de

1889-1890: 20, 26, 28, 38, 50, 54; 1893-1894: 60; $1895-$ 1898: 235; 1899-1900: 10, 19, 150, 151, 161, 172, 173, $175,178,194,197,204,205,215,222$; 1901-1902: 17, $28,52,62,65,69,73,76,86,93,96,120,126,127$. $130,133,135,137,138,143,145,154,155,156,159$, $164,167,183,189,205,221,226,245,247,256,264$, 265, 268-269; 1903-1904: 15, 29, 35, 40, 43, 55, 70, 98, $102,114,158,167,179,206,214,226,271 ; 1905-1906$ : 24, 68; 1909 vol. 1: 53; 1909 vol. 2: 136; 1910 vol. 1: 33, 87; 1910 vol. 2: 35; 1911: 89, 121, 126; 1912: 11, 51, 91, 95, 177, 339; 1913: 91, 201; 1915: 97, 98; 1916: $45-46,50,57,59,61,71,87,115,124,129,152,156$, 158, 190, 191, 195; 1917: 28.

PARIS, Pierre

1910: 31: 1916: 23

QUEIROZ, José

1907-1908: 69, 74, 80,90,105, 116, 149, 157, 191, 270 , 321; 1909 vol.1: 40, 78, 100, 106, 168; 1909 vol. $2: 94$, $118,170,180 ; 1910$ vol.1: 131, 139; 1910 vol. 2: 1, 52, 118, 168; 1911: 147, 215, 295; 1913: 121, 137; 1914: 72; 1915: 278, 288, 299; 1916: 213, 224, 227, 229; 1917: 62 .

QUINTERO ATAURI, Pelayo

1899-1900: 154; 1903-1904: 74, 85; 1907-1908: 263 ; 1909 vol.1: 5, 6, 21, 45, 76, 97, 112, 136, 146, 150; 1909 vol. 2: 2, 10, 26, 38, 68, 69, 150, 154; 1910 vol. 1: $6,8,9,55 ; 1910$ vol. 2 : 75; 1911: 132, 148, 182, 281, 307; 1912: 241, 249, 297; 1916: 62, 69, 101, 122, 132 , 143, 160, 201 1917: 16.

RAMÍREZ DE ARELLANO, Rafael 1893-1894: 90, 94, 109, 112, 129; 1895-1898: 17, 228; 1901-1902: 122, 140; 1903-1904: 45, 47, 95; 19051906: 107, 114, 162, 165; 1909 vol. 2: 3; 1911: 204, 213, 225; 1912: 197, 203, 208, 264, 287; 1914: 141, 157, 243, 255; 1915: 21, 30, 60, 66, 86, 199, 209, 261; 1916: 64, 294; 1917: 11.

RIAÑO, Juan Facundo

1875-1885: 142; 1889-1890: 32, 107, 243; 1891-1892: 88, 111, 117; 1895-1898: 254, 287, 355, 359; $1899-$ 1900: 129.
RODRÍGUEZ CODOLÁ, Manuel:

1907-1908: 264, 276, 281; 1909 vol. 2: 12, 16, 21, 30, $55,56,79,159,168 ; 1910$ vol.1: 56, 63, 75, 97, 146 1910 vol. $2: 21,23,27,34,62,79,93,127,136,156$ 158; 1911: 8, 36, 47, 53, 74, 115, 134, 174, 188, 195 $211,222,239,260,273,294 ; 1912: 6,15,103,142$ 156, 324; 1913: 5, 58, 123, 164, 253; 1914: 51, 153 $184,239,274 ;$; 1915: 59, 105, 266; 1916: 67, 82, 123 270; $1917: 25,46$

\section{ROMERO DE TORRES, Enrique}

1907-1908: 265; 1909 vol.1: 65, 81, 86, 101, 103, 123 131, 139; 1909 vol. $2: 81,93,100,128,186 ; 1910$ vol. 1 $15,91,130,147,148 ; 1911: 104,120,238,269,274$ $296,302,316,320 ; 1912: 38,105,245,323,329,358$ 1913: 70, 85, 130, 133, 196, 212, 226; 1914: 6, 15, 21 $53,81,321,322,325$; 1915: 56, 79, 82, 84, 94, 108 $126,144,145,147,152,156,171,226,228,230,234$ $260,273,295,303 ; 1916: 31,54,159,173,180,183$, $185,186,188,204,222,228,230$.

SENTENACH, Narciso

1875-1885: 19; 1885-1888: 68, 82, 94, 145, 155, 173, 243 1889-1890: 2, 70, 133, 154, 215; 1891-1892: 3, 16, 82, 93 $114,120,158 ; 1893-1894: 51,227,235 ; 1895-1898: 35$ $57,108,121,125,128,131,133,136,168,186,194,199$ $204,221,243,296,318,329,338,343,350,366 ; 1899$ 1900: 60, 92, 99, 118, 127, 164, 223; 1901-1902: 30, 276 278: 1903-1904: 78, 82, 100,111, 127, 140, 155, 208 210, 223, 235, 247, 253, 255, 269, 275; 1905-1906: 42, $77,117,118,137,175,193,197,198,215,253 ; 1907$ 1908: 89, 201, 208, 217, 220, 290; 1909 vol. 1: 33, 99 $110,127,132,137,142,151,156,163,166 ; 1909$ vol. 2 $11,49,110,115,137,174 ; 1910$ vol. 1: 4, 77, 110, 124 1910 vol. $2: 22,45,70,111,125 ; 1911: 3,54,62,108$ bis, $125,130,154,194,202,261,298 ; 1912: 20,74,136,138$ $148,284,305,311$; 1913: 26, 86, 118, 149, 170; 1914: 38, 91, 101, 224, 258bis, 299, 303; 1915: 32, 118, 154, 213 313; 1916: 121, 178, 289; 1917: 33.

SUSILLO, Antonio

1875-1885: 96, 102, 106, 129; 1885-1888: 128; 1893 1894: 224.

TORMO Y MONZÓ, Elías

1907-1908: 106, 113, 130, 154, 172; 1913: 36, 39, 152 1915: 48, 50; 1916: 175, 216, 218, 223, 256; 1917: 34

TRAMOYERES BLASCO, Luis

1895-1898: 324, 331, 335, 342; 1899-1900: 133; $1901-$ 1902: 49, 293; 1907-1908: 169; 1909 vol. 1: 27; 1909 vol. 2: 158; 1910 vol. 1: 119; 1910 vol. 2: 17, 42; 1911 66, 284; 1912: 10; 1913: 61bis, 169.

TUBINO, Francisco $\mathrm{M}^{\mathrm{a}}$

1875-1885: 56, 103, 104, 128, 135; 1885-1888: 10, 11 15, 20bis, 21, 30, 85, 99, 103, 168.

VACA GONZÁLEZ, Diodoro 1911: 33, 50, 69, 326; 1912: 13, 23, 42, 87, 106, 144 144bis, 190, 282, 295, 310; 1913: 7, 21, 57, 61, 79, 97, $99,112,125,142,163,175,203,257 ; 1914: 23,85$ $162,218,278,327$; 1915: 18, 35, 122, 316; 1916: 63 1917: 1, 18, 92, 98

VILLAAMIL Y CASTRO, José

1875-1885: 89, 97, 124, 126: 1885-1888: 104, 112, 125 , $130,137,177,179,187,194,209$; 1889-1890: 12, 19 $27,48,71,163,174,195,201,240,250,253,261$; 1891-1892: 9, 13, 24, 28, 29, 118, 128, 152, 161, 164 181; 1895-1898: 33, 51.

VIVES CISCAR, José

1875-1885: 179, 186, 192, 198; 1885-1888: 9, 16, 49 $60,71,113,123,134,140,147.149,192,201,212$; 1889-1890: 31, 112, 121, 175, 246, 254; 1891-1892: 84, $119,133,141,146$

ZULOAGA, Daniel

1910: 118; 1915: 301; 1916: 5, 29, 98, 99, 100 
